\title{
Effects of a Standard Dose of Fresh Frozen Plasma on Various Elevations in the International Normalized Ratio
}

Emine Akıncı, Şeref Kerem Çorbacıoğlu, Oğuz Yardım, Hüseyin Uzunosmanoğlu, Yunsur Çevik

Clinic of Emergency Medicine, Keçiören Training and Research Hospital, Ankara, Turkey

\begin{abstract}
Aim: This study aimed to determine the effects of using a standard dose of fresh frozen plasma (FFP) on the international normalized ratio (INR) of patients with various elevations in INR from using warfarin.

Materials and Methods: This prospective study was conducted in the emergency department (ED) of a training and research hospital from February 2015 to January 2016 with patients who presented with elevated INRs from using warfarin. Their demographic data, clinical features, and laboratory findings, including pre- and post-transfusion INRs, were recorded. The standard dose of FFP used was 3 units of FFP ( $900 \mathrm{~mL}$ ). Delta INR ( $\triangle I N R)$ was defined as the pre-transfusion INR minus the post-transfusion INR. Two hours after the end of the FFP transfusion, each patient's INR was measured again.

Results: Thirty-two patients who received FFP and whose pre- and post-transfusion INRs were measured were included. Of these 32 patients, 23 ( $71 \%$ ) were women, and the patients' mean age was $72.8 \pm 11.1$. The mean pre- and post-transfusion levels and $\Delta I N R$ were $10.6 \pm 5.3,4.3 \pm 2.3$, and $6.2 \pm 4.3$, respectively. There was a strong positive correlation between high pre-transfusion INR and $\Delta I N R(p<0.001, r=0.85)$. Regression analysis performed to estimate $\Delta I N R$ after the transfusion of a standard dose of FFP found that $\triangle I N R=0.69 \times$ (pre-transfusion INR) -1.111 ( $p<0.001)$.
\end{abstract}

Conclusion: The present study found that using a standard dose of FFP caused varying reductions in $\triangle I N R s$ that correlated with the pre-transfusion INR. (Eurasian J Emerg Med 2016; 15: 78-81)

Keywords: Warfarin, fresh frozen plasma, international normalized ratio, emergency department

\section{Introduction}

Warfarin, a widely used oral anticoagulant, acts by inhibiting vitamin K-dependent coagulation factors and is used to treat several thromboembolic diseases, including atrial fibrillation, deep-venous thrombosis, pulmonary thromboembolism, heart valve replacement, and dilated cardiomyopathy $(1,2)$. The clinical efficacy of warfarin is evaluated by measuring the international normalized ratio (INR) within the determined therapeutic range, which depends on the disease (3). As long as the target INR is achieved and maintained, warfarin therapy has been proven to decrease the risk of thromboembolic events (4). However, one of the foremost challenges in using warfarin is to maintain the target INR within the therapeutic range for the disease under treatment (5). Supra-therapeutic INRs (>3.5) can cause minor or major bleeding. According to the results of previous studies, the most frequent complication of warfarin therapy is hemorrhage necessitating emergency department (ED) treatment $(6,7)$.
In patients with elevated INRs, the treatment options are to stop warfarin therapy, administer oral or intravenous vitamin $\mathrm{K}$, or administer intravenous fresh frozen plasma (FFP). Although FFP is not the first option for treating supra-therapeutic INRs, particularly in patients with major bleeding, it is widely used in EDs to rapidly normalize INRs. Although there is no clear evidence-based data on the dose of FFP required to successfully treat elevated INRs, previous guidelines have recommended $10-15 \mathrm{~mL}$ of plasma per kilogram of body weight $(8,9)$. However, it is the standard dose of FFP to reduce various elevations in INR is not clear. Therefore, this study aimed to determine the effects of using a standard dose of FFP on INRs of patients with various elevations in INR from using warfarin.

\section{Materials and Methods}

This prospective study was conducted in the ED of a training and research hospital from February 2015 to January 2016. The local

Correspondence to: Şeref Kerem Çorbacıoğlu e-mail: serefkeremcorbacioglu@gmail.com 
ethics committee approved the study, and the researchers obtained written informed consent from the patients or their legally authorized relatives.

The study included patients age 18 or older who were admitted to the ED with elevated INRs, either with or without bleeding and who had one or more indications for FFP treatment, which were defined as major bleeding and an elevated INR, minor bleeding that had been unstoppable despite appropriate intervention and an elevated INR, and highly elevated INR ( $>20)$ with or without any other complaints. The study excluded patients younger than the age of 18 , those who did not receive FFP treatment, and those whose pre- and post-transfusion INRs were not measured.

After the patients were initially evaluated, their demographic data, clinical features, and laboratory findings, including pre- and post-transfusion INRs, were recorded. The standard dose of FFP used was 3 units of FFP $(900 \mathrm{~mL})$. The median weight of our patients was 74 (min: 62, max: 85) and the mean of $\mathrm{mL} / \mathrm{kg}$ of FFP body weight was 12.8. Delta INR ( $\triangle I N R)$ was defined as the pre-transfusion INR minus the post-transfusion INR. Two hours after the end of the FFP transfusion, each patient's INR was measured again. After transfusion with a standard dose of FFP, each patient was evaluated for both clinical outcome (stoppable/unstoppable bleeding and/or re-bleeding) and laboratory outcome [decrease to a therapeutic (1.5-3.5) or normal $(<1.5)$ INR]. Patients who continued to bleed after a standard dose of FFP or whose INRs could not be decreased received a second FFP transfusion (3 units of FFP).

\section{Statistical analysis}

Statistical analyses were performed using Statistical Package for the Social Sciences version 15.0 (IBM SPSS Statistics; New York; USA). The Shapiro-Wilk test was used to assess the normal distribution of all parameters related to the patients. The patients' parametric data were expressed as mean and standard deviation (SD). The mean $\triangle I N R$ were analyzed by one-way analysis of variance (ANOVA) in nondependent groups. Pearson's test was used to calculate the correlation between high pre-transfusion INRs and $\Delta I N R$. Finally, to estimate the $\triangle I N R$ after an FFP transfusion, linear regression analysis was performed using the formula $y=a+b x$, where $x=$ [pre-transfusion INR]. A $p$ value of $<0.05$ was considered statistically significant.

\section{Results}

During the study period, 106 patients with elevated INRs were admitted to the ED. Of these, 74 did not receive FFP because they had no major bleeding or other indications; thus, they were excluded. This left 32 patients who both received FFP and whose pre- and post-transfusion INRs were measured. Of these 32 patients, 23 (71\%) were women. The patients' mean age was $72.8 \pm 11.1$ years. Table 1 shows the patients' demographic and clinical characteristics. The mean pre-transfusion INR, post-transfusion INR, and $\triangle I N R$ were $10.6 \pm 5.3,4.3 \pm 2.3$, and $6.2 \pm 4.3$, respectively.

Then, patients were categorized according to their pre-transfusion INRs; eight patients were categorized as having slightly elevated INR (INR=3-6), 12 were categorized as having moderately elevated INR (INR=6-9), and 12 were categorized as having severely elevated INR (INR>12). In addition, $\Delta$ INRs associated with these INRs were 2.15 \pm 0.9 , $5.5 \pm 1.9$, and 9.6 \pm 4.7 , respectively. As Table 2 shows, the differences among all groups were statistically significant (ANOVA, Tamhane, $\mathrm{p}<0.001)$. As Figure 1 shows, there was a strong positive correlation between high pre-transfusion INRs and $\Delta I N R(p<0.001, r=0.85)$. Regression analysis performed to estimate $\Delta \mathrm{INR}$ after transfusion of a standard dose of FFP found that $\triangle I N R=0.69 \times$ (pre-transfusion INR)-1.111 $(p<0.001)$.

Finally, when the data were analyzed according to laboratory outcomes (post-transfusion INR) and clinical outcomes (re-bleeding or unstoppable bleeding), 12 patients' post-transfusion INRs could not be decreased to either therapeutic or normal levels. However, no patients required a second 2-unit FFP transfusion, and no patients experienced re-bleeding or unstoppable bleeding.

\section{Discussion}

This study aimed to detect whether transfusion with a standard dose of FFP decreased INRs in patients whose INRs were elevated due to warfarin use. The study identified two important results. First, it appears that using a standard dose of FFP causes varying reductions in $\Delta I N R s$ in patients whose pre-transfusion

Table 1. Demographic and clinical features of the patients

\begin{tabular}{|c|c|}
\hline Age $($ mean $\pm S D)$ & $72.8 \pm 11.1$ \\
\hline Sex & 23 females $(71 \%)$ \\
\hline \multicolumn{2}{|l|}{ Comorbid diseases, n (\%) } \\
\hline - Hypertension & $24(75)$ \\
\hline - Coronary artery disease & $16(50)$ \\
\hline - Diabetes mellitus & $14(43.8)$ \\
\hline - Congestive heart disease & $12(37.5)$ \\
\hline - Chronic kidney disease & $2(6.3)$ \\
\hline - Other & $9(28)$ \\
\hline \multicolumn{2}{|l|}{ Vital signs (mean \pm SD) } \\
\hline - Systolic blood pressure, $\mathrm{mmHg}$ & $125 \pm 26$ \\
\hline - Diastolic blood pressure, $\mathrm{mmHg}$ & $68 \pm 13$ \\
\hline - Heart rate, beats/min & $91 \pm 11$ \\
\hline \multicolumn{2}{|l|}{ Indication for using warfarin, n (\%) } \\
\hline - Atrial fibrillation & $15(47)$ \\
\hline - Venous thromboembolism & $7(22)$ \\
\hline - Heart valve replacement & $6(19)$ \\
\hline - Other & $4(12)$ \\
\hline \multicolumn{2}{|c|}{ Indication for FFP transfusion, $\mathrm{n}(\%)$} \\
\hline - Major bleeding & $17(53.2)$ \\
\hline - Gastrointestinal hemorrhage & 14 \\
\hline o Intracranial hemorrhage & 2 \\
\hline - Intra-abdominal hemorrhage & 1 \\
\hline - Very high INR (20) & $4(12.5)$ \\
\hline - Unstoppable minor bleeding & $11(34.3)$ \\
\hline Pre-transfusion INRs, mean \pm SD & $10.6(5.3)$ \\
\hline Post-transfusion INRs, mean \pm SD & $4.3(2.3)$ \\
\hline$\Delta \mathrm{INR}$, mean $\pm \mathrm{SD}$ & $6.2(4.3)$ \\
\hline
\end{tabular}


Table 2. $\Delta$ INRs according to different pre-transfusion INR groups

\begin{tabular}{|c|c|c|c|}
\hline $\begin{array}{l}\text { Pre-transfusion } \\
\text { INR group }\end{array}$ & $\begin{array}{c}\text { Number of } \\
\text { patients } \mathrm{n}(\%)\end{array}$ & $\Delta I N R$ & $\mathbf{p}$ \\
\hline$\cdot 3-6$ & $8(25)$ & $2.15 \pm 0.9$ & \\
\hline$\cdot 6-9$ & $12(37.5)$ & $5.5 \pm 1.9$ & $<0.001$ \\
\hline$\cdot>12$ & $12(37.5)$ & $9.6 \pm 4.7$ & \\
\hline
\end{tabular}

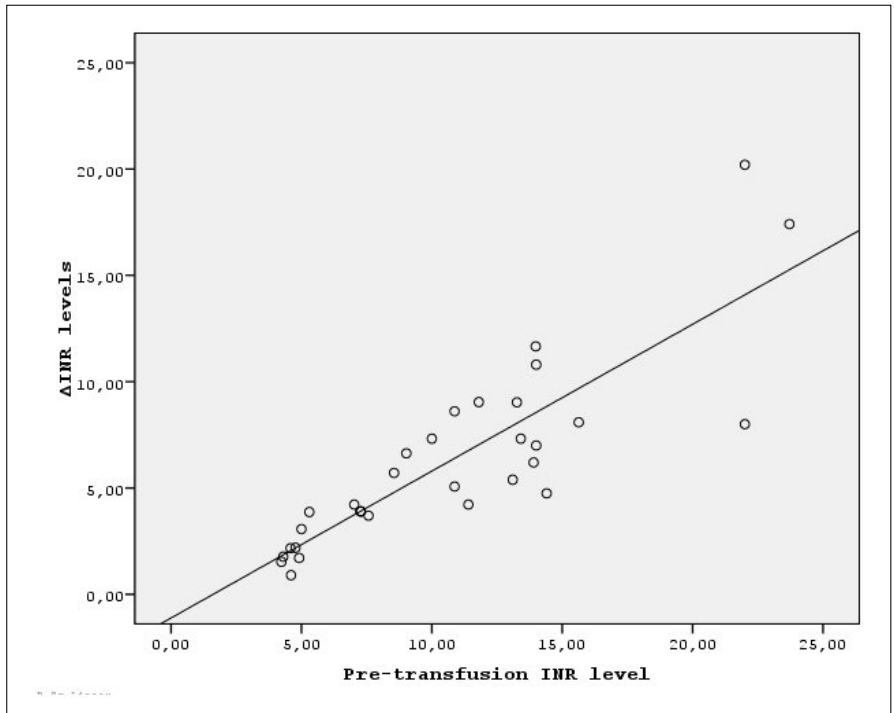

Figure 1. Scatterplot graph showing the correlation between high pre-transfusion INRs and $\Delta \mathrm{INR}(\mathrm{p}<0.001, \mathrm{r}=0.85)$

INRs are elevated to various degrees. Second, despite this first result, using a standard dose of FFP may fail to reduce INRs to therapeutic levels. In 12 patients, post-transfusion INRs could not be decreased to therapeutic levels. However, none of these 12 patients had indications requiring a second FFP transfusion because none of the patients experienced re-bleeding or unstoppable bleeding. Therefore, the findings of the study appear to indicate that a standard dose of FFP is sufficient to safely reduce INRs in patients with both elevated INRs and indications for FFP transfusion. Of course, it must be taken into consideration that this study had a small population; thus, the results may not be enough to extrapolate from.

Two studies, Abdel-Wahab et al. (10) and Holland et al. (11), evaluated $\triangle I N R s$ after 1-unit FFP transfusions in patients with minimally increased INR (in these studies, the pre-transfusion INRs were 1.1-1.85 and 1.1-1.6, respectively). The results showed $\Delta I N R s$ of 0.07 and 0.03 , respectively. Shinagare et al. (12) reported that in patients with moderately increased INR (2.01-5.0), the average $\triangle I N R$ after a 1 -unit FFP transfusion was 0.77 . Sezik et al. (13) reported that in patients who received FFP transfusions due to high INRs, a strong correlation was found between pre-transfusion INRs and $\Delta I_{N R}$-unit FFP $(p<0.0001, r=0.957)$. Holland et al. (14) evaluated the effects of FFP transfusion on laboratory coagulation parameters in 103 patients receiving FFP transfusions due to elevated INRs and found that while FFP transfusion minimally decreased INRs in patients who had minimally increased INRs, it caused more significant decreases in INRs of patients who had higher pre-transfusion INRs. In addition, regression analysis was performed in the study to predict the INR change, and the results showed that INR change $=0.37 \times($ pre-transfusion INR $)-0.47$ (14). As in these previous studies, the present study found a strong positive correlation between elevated pre-transfusion INRs and $\triangle I N R$. In addition, the present study performed a regression analysis to estimate $\Delta I N R$ after transfusion of a standard dose of FFP ( 3 units) and found that $\Delta \mathrm{INR}=0.69 \times$ (pre-transfusion INR) -1.111 .

Currently, modern guidelines recommend prothrombin complex concentrate (PCC) (50 units/kg) as the first option in reversing the effects of warfarin. FFP is only recommended if there is major bleeding and PCC is unavailable. However, PCC is unavailable in our hospital; thus, we have to use FFP to reverse the effects of warfarin.

\section{Study limitations}

The most significant limitation of this study was the small population size. In addition, our study was an observational prospective study and not a randomized controlled study. Our study group mainly comprised geriatric patients who use multi-drugs and have co-morbidities. Therefore, the results may not be sufficient to extrapolate from.

\section{Conclusion}

The present study found that using a standard dose of FFP caused varying reductions in $\Delta I N R s$ with correlated pre-transfusion INRs in patients whose INRs were elevated to varying degrees before transfusion. However, FFP may fail to reduce INRs to therapeutic levels. Considering that none of the patients in the present study experienced re-bleeding or unstoppable bleeding, the findings indicate that a standard dose of FFP is sufficient to safely reduce INRs in patients who have both elevated INRs and indications for FFP transfusion.

Ethics Committee Approval: Ethics committee approval was received for this study from the ethics committee of Keçiören Training and Research Hospital.

Informed Consent: Written informed consent was obtained from patients who participated in this study.

Peer-review: Externally peer-reviewed.

Conflict of Interest: No conflict of interest was declared by the authors.

Financial Disclosure: The authors declared that this study has received no financial support.

\section{References}

1. Limdi NA, Veenstra DL. Warfarin pharmacogenetics. Pharmacotherapy 2008; 28: 1084-97. [CrossRef]

2. Levine M, Pizon AF, Padilla-Jones A, Ruha AM. Warfarin overdose: a 25year experience. J Med Toxicol 2014; 10: 156-64. [CrossRef]

3. Lane DA, Lip GY. Maintaining therapeutic anticoagulation: the importanceof keeping "within range". Chest 2007; 131: 1277-9. [CrossRef]

4. Lip GYH, Edwards SJ. Stroke prevention with aspirin, warfarin, and ximelagatran in patients with non-valvular atrial fibrillation: a systematic review and meta-analysis. Thromb Res 2006; 118: 321-33. [CrossRef]

5. van Walraven $C$, Jennings $A$, Oake N, Fergusson D, Forster AJ. Effect of study setting on anticoagulation control: a systematic review and meta-regression. Chest 2006; 129: 1155-66. [CrossRef] 
6. Sayhan MB, Oğuz S, Yüksel V, Hüseyin S, Sayhan ES, Yağcı G. The Analysis of Patients Admitted to the Emergency Department Dueto Complications Related to Warfarin Treatment. JAEM 2014; 13: 194-8. [CrossRef]

7. Levine MN, Raskob G, Beyth RJ, Kearon C, Schulman S. Hemorrhagic complications of anticoagulant treatment. Chest 2004; 126: 287-310. [CrossRef]

8. O'Shaughnessy DF, Atterbury C, Bolton Maggs P, Murphy M, Thomas D, Yates $S$, et al. Guidelines for the use of fresh-frozen plasma, cryoprecipitate and cryosupernatant. Br J Haematol 2004; 126: 11-28. [CrossRef]

9. Slattery DE, Pollack CV, Thrombotics and Antithrombotics, in: Tintinalli JE, Stapczynski JS, Ma OJ, Yealy DM, Meckler GD, Cline DM (Eds.), Emergengy Medicine: A Comprehensive Study Guide. 8th ed. New York: McGraw-Hill, 2016. pp. 1524-34.

10. Abdel-Wahab OI, Healy B, Dzik WH. Effect of fresh-frozen plasma transfusion on prothrombin time and bleeding in patients with mild coagula- tion abnormalities. Transfusion 2006; 46: 1279-85. [CrossRef]

11. Holland LL, Foster TM, Marlar RA, Brooks JP. Fresh frozen plasmais ineffective for correcting minimally elevated international normalized ratios. Transfusion 2005; 45: 1234-5. [CrossRef]

12. Shinagare SA, Angarkar NN, Desai SR, Naniwadekar MR. An audit of fresh frozen plasma usage and effect of fresh frozen plasma on thepre-transfusion international normalized ratio. Asian J Transfus Sci 2010; 4: 128-32.

13. Sezik S, Aksay E, Kılıç TY. The effect of fresh frozen plasma transfusion on international normalized ratio in emergency department patients. J Emerg Med 2014; 47: 596-600. [CrossRef]

14. Holland LL, Brooks JP. Toward rational fresh frozen plasma transfusion: The effect of plasma transfusion on coagulation test results. Am J Clin Pathol 2006; 126: 133-9.[CrossRef] 